ISSN: $1130-3743$

\title{
LA EVOLUCIÓN DEL CONCEPTO DE SOSTENIBILIDAD Y SU INCIDENCIA EN LA EDUCACIÓN AMBIENTAL
}

\section{The evolution of the concept of sustainability and its effect on environmental education}

\section{L'évolution du concept de développement durable et son incidence dans l'education environnementale}

Pilar Saura Calixto y María Ángeles Hernández Prados

Universidad de Murcia. Facultad de Educación. Departamento de Teoría e Historia de la Educación. Correo-e: mangeles@um.es

Fecha de recepción: enero de 2008

Fecha de aceptación definitiva: abril de 2008

BIBLID [(1130-3743) 20, 2008, 179-204]

RESUMEN

El presente artículo describe la evolución del concepto de sostenibilidad en los textos oficiales de los Organismos Europeos sobre Medio Ambiente. Se identifican tres etapas en la evolución de dicho concepto: 1) modelo de sostenibilidad centrado en los aspectos físico-naturales; 2) modelo de sostenibilidad centrado en la conservación y protección de los recursos naturales, de la fauna y de la flora; 3) modelo de sostenibilidad centrado en el desarrollo humano. Se propone una nueva ética de la sostenibilidad. Asimismo, se describe la evolución del concepto de educación ambiental paralelo al del desarrollo sostenible.

Palabras clave: desarrollo sostenible, medio ambiente, ética, educación ambiental. 


\section{SUMMARY}

This article describes the evolution of the concept of sustainability in the official texts of European environmental organizations. Three phases in this evolution can be identified: 1) the model of sustainability based on the physical environment; 2) the model of sustainability based on the conservation and protection of natural resources; 3) the model based on human development. The evolution of the concept of environmental education in regard to the development of sustainability is described in this work, in addition to a new ethic of sustainability.

Key words: sustainable development, environment, ethics, environmental education.

SOMMAIRE

Cet article décrit l'évolution du concept de développement durable dans les textes officiels des Institutions Européennes sur l'Environnement. Trois étapes ou périodes sont identifiables dans cette évolution: 1) Le modèle de développement durable axé sur les aspects physico-naturels de l'environnement; 2) le modèle de développement durable axé sur la conservation et la protection des ressources naturelles; 3) le modèle axé sur le développement humain. On y propose une nouvelle éthique du développement durable. On y décrit aussi l'évolution du concept d'éducation environnementale parallèlement à celui du développement durable.

Mots clef: développement durable, environnement, éthique, éducation environnementale.

\section{INTRODUCCIÓN}

El problema ambiental es hoy considerado como una de las cuestiones más urgentes a las que se enfrenta la humanidad, sumida en una profunda crisis ecológica y social. Junto a la injusta distribución de la riqueza y los fenómenos de la globalización y migración, la situación de nuestro planeta constituye hoy un problema de tal magnitud (Apple, 1999) que volver la mirada hacia otro lugar, o delegar la respuesta a las futuras generaciones, nos convierte en personas autistas o irresponsables ante un mal del que todos somos responsables.

Si en las décadas pasadas se nos había enseñado a pensar y vivir en un mundo de recursos naturales inagotables, los informes del Club de Roma: Los límites del crecimiento (1975); Factor 4 (1997) y Nuestro futuro común (1992) nos advierten que los recursos naturales son limitados y que los residuos producidos por el consumo cada vez mayor de energía y materias primas ponen en peligro la capacidad de absorción del ecosistema. Hasta ahora, la respuesta a esta situación de "emergencia ambiental" se ha limitado a la restauración de los daños producidos y a la 
prevención de los fenómenos de degradación del medio ambiente. Pero esta respuesta es del todo insuficiente porque deja intactas las causas que producen el "problema ambiental": una concepción de las relaciones ser humano-naturaleza fundada en el dominio y la explotación ilimitada de los recursos naturales, y el sistema económico de producción y distribución de la riqueza, que está generando la sobreexplotación de los recursos naturales en los países pobres y su inevitable degradación (Escámez, García y Pérez, 2003).

La nueva conciencia ambiental se ha traducido en una nueva forma de entender el desarrollo sostenible en el que se implican no solamente la ecología, sino también los diferentes ámbitos de interacción entre individuos, entre éstos y la sociedad y todo el conjunto de sistemas bióticos y también abióticos que integran el medio. Desarrollo sostenible que para el Informe Brundtland significa que se satisfagan las necesidades de la generación presente sin poner en riesgo la capacidad de las generaciones futuras para satisfacer sus propias necesidades. Se hace inaplazable un nuevo concepto de desarrollo sostenible que pasa por un cambio en nuestra relación con la naturaleza y con los demás. Un nuevo estilo de vida que ponga en su base la raíz ética de todo comportamiento, también con la naturaleza (Gómez-Heras, 1997). La promoción de la cultura, la igualdad de posibilidades y el despliegue de las capacidades deben ir acompañadas de la defensa de la naturaleza. El desarrollo de la gente, para la gente y por la gente es la nueva imagen del desarrollo. El desarrollo de la gente significa invertir en capacidades humanas, ya sea en educación, en salud, en vivienda, en condiciones laborales, etc. El desarrollo para la gente significa asegurar que las riquezas generadas por el trabajo de todos se repartan de modo justo y equitativo. El desarrollo por la gente significa que debe centrarse en los seres humanos y debe dar protagonismo a las personas y grupos; que no sólo debe apoyarse en la participación, sino que debe desencadenar la creatividad y las iniciativas de la población. Es falsa la idea, durante tantos años mantenida, que vinculaba crecimiento económico y bienestar de todos (Ortega y Mínguez, 2003). Las grandes bolsas de pobreza han tenido un crecimiento espectacular al mismo tiempo que se producía un elevado crecimiento económico.

Se va asumiendo, si bien lentamente, que el desarrollo económico no es disociable del desarrollo social; que no es posible el desarrollo sostenible del planeta si éste no es extensible a todos, si socialmente no es compartido entre toda la comunidad humana. Insistir en los aspectos económicos del desarrollo prescindiendo de su componente político y sociomoral (Öhman, 2006) es desconocer la naturaleza de los problemas medioambientales que sobrepasan su naturaleza técnica para inscribirse en el ámbito de las construcciones sociales, incidiendo, de este modo, en la calidad de vida y en las necesidades sociales de los individuos. En la era de la globalización ya no es posible sustraer un problema a la influencia de otros problemas. Todo aparece interrelacionado (Papastephanou, 2005). Y ésta es la clave para entender la crisis medioambiental, si sabemos ubicarla «en el marco de una crisis de mayor amplitud que afecta a los pilares del proyecto civilizador de la modernidad" (Caride y Meira, 2001, 36). 
PILAR SAURA CALIXTO Y MARÍA ÁNGELES HERNÁNDEZ PRADOS LA EVOLUCIÓN DEL CONCEPTO DE SOSTENIBILIDAD Y SU INCIDENCIA EN LA EDUCACIÓN AMBIENTAL

Así mismo, se está produciendo un lento pero irreversible cambio de paradigma en el trato a la naturaleza, una nueva reubicación del ser humano en el cosmos. Del ser depredador por excelencia, el ser humano empieza a ser percibido como un viviente más junto a otros vivientes de la misma comunidad biótica (Leopold, 2000); se percibe como un integrante más del ecosistema global, en interdependencia estrecha con el resto de los seres vivos con quienes comparte la aventura de la vida. No es raro encontrar apelaciones a un abandono del paradigma antropocéntrico en las relaciones del ser humano con la naturaleza de modo que el "puesto de éste en el cosmos" no se entienda ya desde una posición de conquista y de dominio, sino la de aquel que vive junto a con los otros seres vivos (GómezHeras, 2005). Ya no se considera al ser humano como el único capaz de reclamar una consideración moral, y su derecho a existir como un bien en sí mismo. También los otros seres vivos merecen un reconocimiento moral en tanto que valen, es decir, poseen valor por sí (Bonnet, 2003). No se trata, por tanto, de que el hombre, en un acto de generosidad, asigne valor a los seres que no lo tienen. "Ver únicamente a los seres humanos como fines en sí mismos, y a todas las demás especies como meros instrumentos al servicio de los intereses humanos, constituye un fallo de imaginación moral" (Jacobs, 1997, 145).

En este trabajo se pretende exponer el itinerario seguido hasta aquí por los Organismos de la Comunidad Europea en la conceptualización del desarrollo sostenible. Cómo el concepto de desarrollo sostenible se ha ido desplazando desde aspectos estrictamente "naturalistas" y económicos hasta abarcar componentes sociomorales. Es, en definitiva, la pequeña historia del desarrollo hasta llegar a ser "Sostenible". Se observará un lento caminar hacia un concepto de desarrollo más acorde con las necesidades y sensibilidades de los ciudadanos. Ha sido, y está siendo, una laboriosa construcción colectiva para una mejor relación entre los humanos y de éstos con la naturaleza que, sin duda, las generaciones futuras sabrán reconocer. Sólo cuando se conoce el camino recorrido para "llegar hasta aquí" se valora más el trabajo realizado y los resultados conseguidos, y lo mucho que aún queda por hacer.

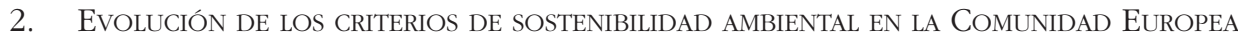

El concepto de desarrollo sostenible no es estático. Ha ido evolucionando paralelamente al desarrollo científico tecnológico y humano, admitiendo múltiples interpretaciones, manteniéndose progresivamente como un marco de intenciones ya que, en la práctica, no podemos hablar todavía de un modelo acabado. Trataremos de interpretar los pronunciamientos y las recomendaciones de los Organismos de la Comunidad Europea para comprender los cambios que se han ido dando, desde los primeros enfoques "ambientalistas", próximos a las ciencias de la naturaleza y económicos, hasta aquellos que se orientan hacia la captación de la complejidad del entramado ecológico, económico y social, en un enfoque global 
y equilibrado. La progresiva concienciación e inquietud por el tema del medio ambiente, así como los pronunciamientos a partir de los cuales podemos juzgar el proceso que ha tenido lugar hasta desembocar en la idea de desarrollo sostenible que hoy inspira la actuación comunitaria, tiene sus inicios en los años 50 y 60 con los Tratados Fundacionales de las Comunidades Europeas (CEE, CECA, EURATOM).

Podemos distinguir tres etapas en las que aparecen diferentes planteamientos sobre el desarrollo sostenible. A nivel conceptual, es posible distinguir entre períodos. Sin embargo, somos conscientes de la dificultad que supone incluir cada uno de los pronunciamientos realizados en foros europeos sobre el tema en un período concreto dado que, en muchos casos, se avanzan cuestiones que suponen un adelanto con respecto a su tiempo.

El primer período en el proceso evolutivo de formación del concepto de sostenibilidad se caracteriza por la concienciación sobre la degradación del medio ambiente, que se manifiesta en distintos pronunciamientos centrados en aspectos físico-naturales del medio a partir de planteamientos cercanos a las ciencias de la naturaleza. El segundo período centra su atención en cuestiones relacionadas con la conservación de recursos naturales y protección de la naturaleza. En el tercer período aparecen nuevos planteamientos sobre desarrollo humano sostenible y se caracteriza por: concienciación sobre las relaciones entre hombre y medio ambiente donde se implican dimensiones culturales, sociales, económicas y políticas; interdependencia entre medio ambiente y desarrollo; preocupación no sólo por el uso racional de los recursos naturales sino también por el reparto de los mismos. En este contexto, se plantea el papel fundamental de la educación para el logro de objetivos de sostenibilidad ambiental. En el Cuadro I quedan reflejados los principales hitos en la evolución de los criterios de sostenibilidad a partir de las formulaciones en las que aquéllos se hacen patentes.

\subsection{Modelo de sostenibilidad centrado en aspectos físico-naturales del medio}

La sensibilización por los problemas ambientales, motivada principalmente por el aumento de la contaminación mundial, tiene su inicio en la década de los 60 y continúa en los 70. En esta época se consiguen acuerdos internacionales que responden al deseo de prevenir la contaminación marina ("Convenio de Oslo para el Atlántico Norte» de 1972 y "Convenio de Londres”, de 1973, sobre prevención de vertidos de sustancias perjudiciales, etc.). Toda esta corriente a favor del medio ambiente, que se produce a nivel mundial, repercute también en Europa, aunque en un principio la protección del medio no constituya un objetivo a conseguir en los Tratados Fundacionales de las Comunidades Europeas. A principios de la década de los 70 se toma conciencia del problema que supone el agotamiento de los recursos naturales y se empiezan a utilizar conceptos como calidad de vida. En el año 1978, el Parlamento Europeo elabora una iniciativa tendente a analizar la 
PILAR SAURA CALIXTO Y MARÍA ÁNGELES HERNÁNDEZ PRADOS

LA EVOLUCIÓN DEL CONCEPTO DE SOSTENIBILIDAD Y SU INCIDENCIA EN LA EDUCACIÓN AMBIENTAL

política y legislación de los Estados miembros sobre la lucha contra la contaminación atmosférica, hídrica y acústica.

El modelo de desarrollo posterior a la Segunda Guerra Mundial contribuye notablemente a la degradación del medio ambiente. Como reacción a esta situación de insostenibilidad ambiental tiene lugar la primera "Conferencia de Naciones Unidas sobre Medio Ambiente" que se celebra en Estocolmo, en junio de 1972, versando sobre el medio humano. En ella se establece la necesidad de protección del medio ambiente a nivel mundial, aunque en realidad todo quedará en una mera declaración de intenciones. En la Declaración final de la citada Conferencia se afirma: "Hemos llegado a un momento en la historia en el que debemos orientar nuestros actos en todo el mundo atendiendo con mayor cuidado a las consecuencias que puedan tener para el medio" y establece 26 principios básicos, planteando, por primera vez, que el problema del medio ambiente es fundamentalmente un problema de las naciones industrializadas, y que el desarrollo económico existente es altamente depredatorio de los recursos naturales por lo que se hacen inevitables fuertes cambios en los modos de producción, distribución y consumo. Cabe aquí mencionar que entre algunas de las resoluciones y recomendaciones finales de la citada "Conferencia de Estocolmo" se propone la necesidad de desarrollar, a escala mundial, programas de educación ambiental (Principio 19). Esta tarea fue asumida por la ONU en 1974, creando el "Programa de Naciones Unidas de Educación Ambiental" que fue aplicado a partir de 1975 por la UNESCO (PNUMA-UNESCO). También se alude en este foro a la dimensión social implícita en el desarrollo sostenible (Principios 8 y 9), en los siguientes términos: "La mayoría de los problemas ambientales están motivados por el subdesarrollo"; "Los países industrializados deben esforzarse en reducir la distancia que los separa de los países en desarrollo". En el Principio 8 de la "Declaración de Estocolmo" se afirma que: "el desarrollo económico y social es indispensable para asegurar al hombre un ambiente de vida y trabajo favorable y crear en la Tierra las condiciones necesarias para mejorar la calidad de vida". En el Principio 9, se expresa la convicción de que la mejor manera de subsanar los graves problemas originados por los desastres naturales es el desarrollo acelerado en el que se impliquen el esfuerzo interno de los países en desarrollo y la ayuda que pueda requerirse.

En todos estos pronunciamientos subyace la idea de que es posible un desarrollo económico ilimitado que fundamenta una actitud optimista ante los problemas al considerar que se está en posesión de los medios necesarios para solucionarlos. A partir de aquí, se constata, a nivel mundial y no sólo europeo, el nacimiento de una nueva conciencia ante la degradación del medio ambiente y la preocupación por su conservación que se pone de manifiesto en la citada "Conferencia de Estocolmo". Después de la celebración de dicha Conferencia, en octubre de 1972, se celebra una Reunión de Jefes de Estado y Gobierno de los Estados miembros de la Comunidad Europea, la llamada "Cumbre de París", de la que surge una declaración política en la que se recoge la importancia de la problemática 
ambiental y se encomienda a las instituciones comunitarias la elaboración de un programa de acción en materia de medio ambiente.

La actuación comunitaria, a partir de la Cumbre de París, se estructura sobre la base de consecutivos programas de acción que se constituyen como marco de referencia a las acciones específicas de la Comunidad. El "Primer Programa Plurianual Comunitario en Materia de Medio Ambiente" (de 1973 a 1977) y el "Segundo Programa" (1978 a 1982), se centran en el problema de la contaminación. En estos Programas se establecen una serie de principios básicos para el logro de la sostenibilidad, aludiendo de forma expresa a la necesidad de fomentar la educación ambiental, aunque a nivel práctico la atención se dirige fundamentalmente a la información o incluso formación en torno a los temas que preocupan. Los principios que se proponen aluden a la conveniencia de políticas ambientales preventivas en lugar de medidas que remedien y combatan a posteriori la contaminación, a la aplicación del conocimiento científico para fundamentar acciones eficaces, a la necesidad de que los Estados miembros, en su política medioambiental, tengan en cuenta los intereses de países en vías de desarrollo, al principio de subsidiariedad (las medidas de protección ambiental se adoptarán según los diferentes grados de contaminación, teniendo en cuenta el tipo de contaminación y la zona).

Los resultados obtenidos de la puesta en práctica de estos primeros programas de acción han sido diversos. Como logros positivos pueden apuntarse el incremento de la normativa comunitaria tendente a la reducción de los agentes contaminantes, la aplicación práctica de nuevos instrumentos de intervención en materia ambiental, la realización y coordinación de investigación relacionada con la mejora del ambiente, la sensibilización de la opinión pública y la participación de las Comunidades en convenciones internacionales en torno al medio ambiente en las que se ha mantenido una posición única en lugar de las que corresponderían a los Estados miembros de asistir por separado. Como factores menos favorables se han puesto de manifiesto los siguientes: falta de voluntad política y diferencias significativas de puntos de vista en los Estados miembros. Igualmente, se ha constatado una desproporción notable entre los programas y los medios disponibles para su ejecución, así como una gran divergencia entre las técnicas y métodos aplicados en los diferentes Estados miembros (Molina del Pozo, 2002). 
PILAR SAURA CALIXTO Y MARÍA ÁNGELES HERNÁNDEZ PRADOS LA EVOLUCIÓN DEL CONCEPTO DE SOSTENIBILIDAD Y SU INCIDENCIA EN LA EDUCACIÓN AMBIENTAL

MODELO DE SOSTENIBILIDAD CENTRADO FUNDAMENTALMENTE EN ASPECTOS Fí́SICO-NATURALES DEL MEDIO

\begin{tabular}{|c|c|c|c|}
\hline Años & Situación & Foros & $\begin{array}{l}\text { Planteamientos y } \\
\text { recomendaciones }\end{array}$ \\
\hline $50-60-70$ & $\begin{array}{l}\text { - Aumento de } \\
\text { contaminación } \\
\text { - Concienciación } \\
\text { sobre la degra- } \\
\text { dación del } \\
\text { medio ambiente }\end{array}$ & $\begin{array}{l}\text { - Tratados fundacionales de } \\
\text { las Comunidades Euro- } \\
\text { peas (CEE, 1950) } \\
\text { - Iniciativa del Parlamento } \\
\text { Europeo sobre contami- } \\
\text { nación atmosférica (1968) } \\
\text { - Convenio de Oslo para el } \\
\text { Atlántico Norte (1972) } \\
\text { - Conferencia de Naciones } \\
\text { Unidas sobre Medio } \\
\text { Ambiente. Estocolmo } \\
\text { (1972) } \\
\text { - Cumbre de París (1972) } \\
\text { - Convenio de Londres } \\
\text { (1973) } \\
\text { - Primer Programa Pluria- } \\
\text { nual Comunitario en } \\
\text { materia de Medio } \\
\text { Ambiente (1973 a 1977) } \\
\text { - Segundo Programa Pluria- } \\
\text { nual Comunitario en } \\
\text { materia de Medio } \\
\text { Ambiente (1977 a 1982) }\end{array}$ & $\begin{array}{l}\text { - Prevenir la contami- } \\
\text { nación por vertidos } \\
\text { al mar } \\
\text { - Prestar mayor aten- } \\
\text { ción a las consecuen- } \\
\text { cias de nuestros actos } \\
\text { y sus consecuencias } \\
\text { para el medio } \\
\text { ambiente } \\
\text { - Analizar política y } \\
\text { legislación medioam- } \\
\text { biental en los Estados } \\
\text { miembros sobre la } \\
\text { lucha contra la conta- } \\
\text { minación atmosférica, } \\
\text { hídrica y acústica } \\
\text { - Proteger los recursos } \\
\text { naturales en benefi- } \\
\text { cio de generaciones } \\
\text { presentes y futuras }\end{array}$ \\
\hline
\end{tabular}

\subsection{Modelo de sostenibilidad centrado en la conservación y protección de recursos naturales, fauna y flora}

Como consecuencia del trabajo que se había realizado hasta el momento y manteniendo el gran objetivo perseguido por las Comunidades en su política ambiental de mejorar el hábitat, la calidad de vida de los ciudadanos y las condiciones de espacio vital de los pueblos de las Comunidades, se adopta el "Tercer Programa Comunitario de Acción en materia de Medio Ambiente" (de 1983 a 1986). En concreto, el Tercer Programa hace referencia a: reducción de toda forma de polución, contaminación o atentado contra el medio atmosférico hasta niveles que supongan una cota aceptable para la colectividad; economizar ciertas materias primas no renovables y afrontar el reciclado de desechos y la búsqueda de alternativas menos contaminantes; ampliar la dimensión del concepto de medio ambiente y cooperación tanto con Organismos Internacionales como con terceros países en desarrollo para la lucha contra la contaminación y, en general, de todo deterioro 
del ambiente. Es de destacar en este "Tercer Programa" la recomendación sobre la integración de la protección medioambiental en otras políticas comunitarias con el fin de impulsar el desarrollo sostenible.

En julio de 1987 tiene lugar la primera modificación del "Tratado de Roma" por el "Acta Única Europea". En ella se articula la base jurídica para el desarrollo de medidas comunitarias sobre medio ambiente. Dicha Acta Única, en la parte tercera del Tratado, incluye el Título VII, "Medio Ambiente", en el que se relacionan una serie de objetivos en los que, en todo caso, debe basarse la acción comunitaria en lo relativo al medio ambiente. Entre otros principios se establece el de "Integración del medio ambiente en otras políticas comunitarias". Como objetivos se marcan los de conservar, proteger y elevar la calidad medioambiental, contribuir a proteger la salud de las personas y utilizar racionalmente los recursos naturales. En cualquier caso, el principio de integración del medio ambiente en las demás políticas puede considerarse la medida más importante del título de "Medio Ambiente".

En 1987, la "Comisión Mundial para el Medio Ambiente y el Desarrollo", formada por más de cien expertos, creada en el año 1983 por la ONU, elabora el Informe Brundtland "Nuestro futuro común". En él se habla, por primera vez, del desarrollo sostenible como "aquel que satisface las necesidades de la generación presente sin comprometer la capacidad de las generaciones futuras para satisfacer sus propias necesidades". Señala, igualmente, que la búsqueda del desarrollo sostenible requiere: un sistema político que asegure la participación ciudadana efectiva en la toma de decisiones; un sistema económico capaz de generar excedentes y conocimiento técnico sostenido; un sistema social que prevea soluciones a las tensiones originadas por un desarrollo inarmónico; un sistema de producción que respete la obligación de preservar la base ecológica para el desarrollo; un sistema tecnológico que pueda aportar continuamente nuevas soluciones; un sistema internacional que fomente patrones sostenibles de comercio y finanzas y un sistema administrativo flexible con capacidad de corregirse así mismo. En dicho Informe se vislumbra ya el principio de desarrollo sostenible que implica hacer compatibles el crecimiento económico, la cohesión social y protección del medio ambiente, con la finalidad de no comprometer la supervivencia de los ecosistemas y de las generaciones futuras, y permitir el acceso global a una vida digna. El Principio 5 de este Informe se ocupa de dar prioridad a la situación y necesidades especiales de los países en desarrollo, en especial los países menos adelantados y los más vulnerables desde la perspectiva ambiental. En el Principio 7 se señalan los valores ambientales de cooperación y solidaridad como necesarios para conservar, proteger y restablecer la salud e integridad del ecosistema Tierra. Hemos de reconocer, no obstante, que en estos planteamientos la idea que subyace tiene que ver con el crecimiento económico ilimitado como medio para conseguir el desarrollo de países pobres, idea alejada de la realidad ya que los recursos naturales son limitados.

En mayo de 1988, los ministros de la CEE de Educación, reunidos en Consejo, elaboran una Resolución sobre la educación en materia de medio ambiente, conscientes de la importancia creciente que reviste la protección del entorno con vistas 
PILAR SAURA CALIXTO Y MARÍA ÁNGELES HERNÁNDEZ PRADOS

LA EVOLUCIÓN DEL CONCEPTO DE SOSTENIBILIDAD Y SU INCIDENCIA EN LA EDUCACIÓN AMBIENTAL

MODELO DE SOSTENIBILIDAD CENTRADO FUNDAMENTALMENTE EN LA CONSERVACIÓN Y PROTECCIÓN DE RECURSOS NATURALES, FAUNA Y FLORA

\begin{tabular}{|c|c|c|c|}
\hline Años & Situación & Foros & $\begin{array}{l}\text { Planteamientos y } \\
\text { recomendaciones }\end{array}$ \\
\hline $70-80$ & $\begin{array}{l}\text { - Concienciación } \\
\text { sobre la necesi- } \\
\text { dad de protec- } \\
\text { ción y } \\
\text { conservación del } \\
\text { medio ambiente } \\
\text { - Planteamiento } \\
\text { del carácter } \\
\text { global de los } \\
\text { problemas } \\
\text { ambientales } \\
\text { - Defensa del } \\
\text { planeta desde el } \\
\text { punto de vista } \\
\text { ecológico } \\
\text { - Centralidad del } \\
\text { problema } \\
\text { ambiental en la } \\
\text { naturaleza. } \\
\text { Planteamientos } \\
\text { cercanos a la } \\
\text { idea de que el } \\
\text { crecimiento de } \\
\text { la economía es } \\
\text { ilimitado } \\
\text { - Preocupación } \\
\text { por el desarrollo } \\
\text { de países más } \\
\text { vulnerables } \\
\text { desde la } \\
\text { perspectiva } \\
\text { ambiental }\end{array}$ & $\begin{array}{l}\text { - Tercer Programa } \\
\text { Comunitario de } \\
\text { Acción en materia } \\
\text { de Medio } \\
\text { Ambiente (1983 a } \\
\text { 1986) } \\
\text { - Primera modifica- } \\
\text { ción del Tratado } \\
\text { de Roma por el } \\
\text { Acta Única } \\
\text { Europea } \\
\text { - Informe Brund- } \\
\text { tland. «Nuestro } \\
\text { Futuro Común". } \\
\text { Comisión Mundial } \\
\text { para el Medio } \\
\text { Ambiente y Desa- } \\
\text { rrollo (1987) } \\
\text { - Resolución sobre } \\
\text { la Educación en } \\
\text { Materia de Medio } \\
\text { Ambiente. Minis- } \\
\text { tros de Educación } \\
\text { reunidos en Con- } \\
\text { sejo (1988) } \\
\text { - Cuarto Programa } \\
\text { Comunitario de } \\
\text { Acción en Materia } \\
\text { de Medio } \\
\text { Ambiente (1987 a } \\
\text { 1992) }\end{array}$ & $\begin{array}{l}\text { - Es preciso proteger el medio } \\
\text { ambiente a nivel mundial } \\
\text { - Elaboración de Programas para la } \\
\text { intervención en materia de medio } \\
\text { ambiente } \\
\text { - Se propone una estrategia global } \\
\text { para el logro del desarrollo } \\
\text { sostenible a partir de la cooperación } \\
\text { mundial } \\
\text { - Se considera el crecimiento } \\
\text { económico como algo ilimitado } \\
\text { - Se propone una política ambien- } \\
\text { tal preventiva. La prevención se } \\
\text { constituye en objetivo básico } \\
\text { - Se recomienda evitar daños al } \\
\text { equilibrio ecológico con la } \\
\text { explotación de recursos naturales } \\
\text { - Es preciso aplicar el conoci- } \\
\text { miento científico para lograr } \\
\text { acciones eficaces } \\
\text { - Se establece el principio de } \\
\text { subsidiariedad } \\
\text { - Es preciso coordinar políticas } \\
\text { nacionales con las comunitarias, } \\
\text { sobre medio ambiente } \\
\text { - Redefinir principios y objetivos } \\
\text { básicos de la política ambiental } \\
\text { - Sensibilizar de cara a los proble- } \\
\text { mas relativos a la conservación y } \\
\text { mejora del medio ambiente } \\
\text { - Fomento de la formación y } \\
\text { educación en materia de medio } \\
\text { ambiente } \\
\text { - Se establecen los principios sobre } \\
\text { derechos y responsabilidades de } \\
\text { las naciones en el progreso y } \\
\text { bienestar de la humanidad } \\
\text { - Integración en las legislaciones } \\
\text { comunitaria y nacional de las } \\
\text { exigencias ambientales } \\
\text { - Reducción de la contaminación }\end{array}$ \\
\hline
\end{tabular}


a mejorar las condiciones de vida. El objetivo marcado es el de intensificar la sensibilización del ciudadano de cara a los problemas relativos a la conservación y mejora del medio ambiente a través de medidas adecuadas en el ámbito educativo. Declaran que es importante concertar la actuación comunitaria en determinados sectores, dando prioridad al fomento de la educación y formación en materia de medio ambiente. Por ello, recomiendan tomar medidas encaminadas a mejorar la correspondencia entre los sistemas educativos, intensificando iniciativas en este ámbito, dada la creciente demanda de personal con conocimientos especializados en cuestiones relativas a la protección del medio ambiente. Acuerdan determinados principios sobre educación ambiental, señalando la conveniencia de instituir intercambios sistemáticos de información y experiencias en la Comunidad, tomando en consideración las características regionales y las posibilidades de participación y cooperación en la protección del medio ambiente, debiendo, así mismo, tomarse en consideración el hecho de que la educación en materia de medio ambiente es una materia interdisciplinar. Hemos de reconocer, sin embargo, que dicha Resolución trata de acentuar el papel de la "información" sobre los desastres ecológicos producidos por la actividad humana y de fomentar el "intercambio" de experiencias y formación, más que de impulsar la competencia moral de los individuos para una cultura medioambiental.

\subsection{Nueva ética de la sostenibilidad. Modelo de desarrollo bumano}

En 1992, se celebra en Río de Janeiro la Conferencia de Naciones Unidas ("La Cumbre de la Tierra") sobre Medio Ambiente y Desarrollo en la que se acuerda una estrategia global para lograr un desarrollo sostenible a partir de la cooperación mundial, estableciéndose 27 principios sobre derechos y responsabilidades de las naciones en el progreso y bienestar de la humanidad. Entre los principios establecidos en la Conferencia de Río, se afirma que "los seres humanos constituyen el centro de las preocupaciones relacionadas con el desarrollo sostenible. Tienen derecho a una vida saludable y productiva en armonía con la naturaleza". A propósito de esta cuestión, Álvarez Díaz (2001) señala que el medio ambiente no es un concepto abstracto, sino que representa el espacio viviente, la calidad de vida y la salud misma de los seres humanos. Por ello, parece adecuado hablar del medio ambiente como un verdadero derecho de todo ser humano. Efectivamente, a partir de la Conferencia de Río, en la que se produce la consolidación del concepto de desarrollo sostenible, se pone de relieve el "derecho internacional del desarrollo sostenible" junto al "derecho internacional del medio ambiente" (Principios 2 y 3). En este foro expertos de todo el mundo acuerdan el documento: "Tratado de Educación Ambiental para Sociedades Sustentables y Responsabilidad Global” a fin de integrar la educación ambiental en el desarrollo sostenible.

En el "Tratado de Maastricht", firmado en febrero de 1992 por los ministros de Asuntos Exteriores de los 12 países miembros, tras el acuerdo alcanzado por los 
PILAR SAURA CALIXTO Y MARÍA ÁNGELES HERNÁNDEZ PRADOS LA EVOLUCIÓN DEL CONCEPTO DE SOSTENIBILIDAD Y SU INCIDENCIA EN LA EDUCACIÓN AMBIENTAL

Jefes de Estado y Gobierno, en la Cumbre celebrada en la citada ciudad holandesa, el Tratado de la UE experimenta una notable reforma que entra en vigor en noviembre de 1995. Los acuerdos tomados en materia medioambiental suponen un gran avance en cuanto al desarrollo sostenible, haciendo hincapié en la protección del medio ambiente y la integración de este concepto en todas las políticas comunitarias.

El "Cuarto Programa Comunitario de Acción en Materia de Medio Ambiente" (de 1987 a 1992), vuelve a incidir sobre el tema de la integración del medio ambiente en otras políticas comunitarias, destacando nuevos compromisos para conseguir dicha integración. Las orientaciones que se señalan en el mismo versan sobre el desarrollo y la aplicación, lo más amplia posible, del principio de responsabilidad de que quien contamine pague; prevención como objetivo básico de la política ambiental; integración en las legislaciones comunitarias y nacional de las exigencias en materia de medio ambiente; asistencia a regiones desfavorecidas y zonas industriales en declive; reducción de la contaminación del aire y del mar con la puesta a punto, a escala mundial, de códigos de prácticas relativas a productos químicos, residuos e instalaciones peligrosas; adopción de reglamentos adecuados al sector de la biotecnología; mantenimiento y armonización, a nivel comunitario, de las normas de prevención de productos contaminantes del ambiente; lanzamiento de un programa quinquenal de proyectos de demostración tendentes a explotar el potencial de creación de empleos ofrecido por las políticas en materia de medio ambiente; y reforzamiento del papel crucial de la Comunidad en esta materia, particularmente en lo relativo a problemas específicos de los países en vías de desarrollo.

Todos estos acuerdos suponen un hito importante en relación a una nueva sensibilidad hacia el uso racional de los recursos. En este contexto, tiene lugar el "Quinto Programa Comunitario de Acción en Materia de Medio Ambiente", en el que se resalta la acción de la Unión Europea, en el ámbito del medio ambiente, desde el año 1995 hasta el 2000. Entre los principios inspiradores de este Programa se proponen los de establecer un enfoque global y constructivo para la integración de las exigencias ambientales en las diferentes políticas comunitarias para el logro de un desarrollo sostenible, haciendo hincapié en el principio de responsabilidad compartida que supone el compromiso voluntario de las partes sociales y económicas intervinientes (administraciones, gobiernos, organizaciones no gubernamentales, entidades y agentes financieros y sociales), así como de los ciudadanos en general, en el logro del cambio de comportamiento social. Merece especial mención la atención que se presta, en este foro, a la información y a su difusión, y sobre todo a la educación ya que no es posible plantear o conseguir los objetivos que se proponen sin que sean asumidos e interiorizados los nuevos principios por los agentes sociales y económicos. En este contexto, se proponen algunos modos de acelerar el proceso de cambio estructural citando como principio la reorientación de la investigación fundamental. Las propuestas planteadas en el Quinto Programa son consideradas años mas tarde por la Comisión. Concretamente, a los 
tres años de la entrada en vigor del Programa, en la "Cumbre de Helsinki", la Comisión publicó un informe sobre su efectividad y aplicación (Informe de la Comisión sobre la Aplicación del Programa Comunitario de Política y Actuación en Materia de Medio Ambiente y Desarrollo Sostenible, "Hacia el desarrollo sostenible"). En dicho Informe, se destaca la necesidad de introducir modificaciones que permitan alcanzar una mayor eficacia. También se pone de manifiesto la falta de progresos por lo que se refiere a la integración de las exigencias medioambientales.

El "Tratado de Ámsterdam", firmado por los Jefes de Estado y Gobierno de los Estados miembros, en octubre de 1997, entró en vigor en mayo de 1999. En él se revisa el "Tratado Constitutivo de la Comunidad Europea", consolidando la idea de desarrollo sostenible, dejando, a partir de ahora, de constituir una opción para convertirse en obligación. Así, en el artículo 2 del citado Tratado, se establece como uno de los objetivos de la Unión el "promover el progreso económico y social y un alto nivel de empleo y conseguir un desarrollo equilibrado y sostenible, principalmente mediante la creación de un espacio sin fronteras interiores, el fortalecimiento de la cohesión económica y social y el establecimiento de una unión económica y monetaria". En estos pronunciamientos se pone de manifiesto una nueva perspectiva, en cierta medida ya vislumbrada con anterioridad, en la que se trasciende la idea de protección y conservación del medio ambiente, centrándose en el debate social sobre el desarrollo humano y la interacción entre medio ambiente y desarrollo. Se plantean como objetivos: la conservación, protección y mejora de la calidad del medio ambiente; la protección de la salud de las personas; la utilización prudente y racional de recursos naturales; y el fomento de medidas a escala internacional para hacer frente a problemas regionales o mundiales del medio ambiente. Así mismo, se señala que la política ambiental de la Comunidad deberá propiciar la acción preventiva, corrección de atentados al medio ambiente, preferentemente en el origen mismo, y el principio de "Quien contamina paga". En la elaboración de políticas de carácter medioambiental se tendrán en cuenta: datos científicos y técnicos disponibles; condiciones del medio ambiente en las diversas regiones de la Comunidad; ventajas e inconvenientes que pueden deducirse de la acción o falta de acción. Igualmente, en este Tratado se establece que los Estados miembros tendrán a su cargo la financiación y ejecución de la política en materia de medio ambiente. Como aspecto a destacar, señalamos la exigencia, no sólo la recomendación, de incorporar criterios a favor del medio ambiente en todas las políticas comunitarias, en los siguientes términos: "las exigencias de la protección del medio ambiente deberán integrarse en la definición y en la realización de las políticas y acciones de la Comunidad".

Años más tarde, la Comisión hace público un comunicado en el que se realiza una evaluación global de los resultados y el éxito alcanzado por el "Quinto Programa" (Comunicación de la Comisión relativa a la evaluación global del Programa Comunitario de Política y Actuación en materia de Medio Ambiente y Desarrollo Sostenible - «Hacia un desarrollo sostenible»-). En el mismo se afirma que la protección del medio ambiente en el contexto comunitario ha experimentado un 
PILAR SAURA CALIXTO Y MARÍA ÁNGELES HERNÁNDEZ PRADOS

LA EVOLUCIÓN DEL CONCEPTO DE SOSTENIBILIDAD Y SU INCIDENCIA EN LA EDUCACIÓN AMBIENTAL

avance, y las políticas comunitarias han logrado reducir la contaminación atmosférica transfonteriza, se ha aumentado la calidad del agua y se han eliminado sustancias que disminuyen la capa de ozono. Sin embargo, el avance ha sido limitado debido a que ni los Estados miembros, ni los sectores contemplados por el Programa llegaron a tener en cuenta realmente las preocupaciones medioambientales, ni a integrarlas en sus políticas. Este comunicado terminaba afirmando que "La Unión dista mucho de haber alcanzado el ambicioso objetivo de un desarrollo sostenible que se fijó en el Tratado de Ámsterdam", por lo que anuncia la apertura de un debate con las demás instituciones, las partes interesadas y los ciudadanos en torno a las prioridades de un VI Programa sobre medio ambiente.

En diciembre de 1997 se celebra la "Cumbre de Luxemburgo" en la que se solicita a la Comisión Europea que elabore una estrategia para la aplicación de las exigencias del Tratado de Ámsterdam. En respuesta al mandato del Consejo Europeo se publica el documento: “Colaboración para la integración”. Constituye una estrategia para la integración del medio ambiente en las políticas de la Unión Europea y presenta diversos criterios prácticos para introducir el principio de integración del medio ambiente en todas las Políticas de forma transversal. El mismo es presentado al Consejo Europeo en la "Cumbre de Cardiff", celebrada en junio de 1998. Entre las recomendaciones concretas a que alude dicho comunicado se establece la de "examinar la integración del medio ambiente en las políticas sectoriales". Igualmente, la Comisión considera que la integración de criterios ambientales en las políticas sectoriales comunitarias debe hacerse con cuidado, proponiendo un proceso gradual de elaboración de estrategias parciales por los diferentes sectores. En este sentido, el "Consejo Europeo de Bruselas", celebrado en la primavera del 2004, vuelve a insistir en la importancia de la integración medioambiental en los siguientes términos: "Para que el crecimiento sea sostenible, debe ser racional desde la perspectiva medioambiental. Deberá disociarse el crecimiento económico de las consecuencias negativas para el medio ambiente".

Otra cuestión a tener en cuenta sobre las recomendaciones emanadas del documento: "Colaboración para la integración", antes mencionado, es la consideración sobre la necesidad de dar prioridad, con carácter de urgencia, a la "Agenda 2000", programa de acción cuyos objetivos principales son reforzar la política comunitaria y dotar a la Unión Europea de un nuevo marco financiero para el período 2000-2006, así como la puesta en práctica del protocolo de Kioto (La aplicación de los compromisos adquiridos en el marco de este protocolo requiere un planteamiento integrado. Los Estados signatarios se comprometieron a reducir los gases de efecto invernadero para los años 2008-2012, con el fin de luchar contra el calentamiento de la Tierra). Por ello, la protección y mejora del medio ambiente constituye uno de los objetivos prioritarios en el futuro de los Fondos Estructurales para el desarrollo sostenible. También destacan, en el citado documento, las propuestas para la elaboración por cada sector de sus propias estrategias de integración de criterios medioambientales y desarrollo sostenible en las políticas de su competencia. 
En diciembre de 1998 tiene lugar la "Cumbre de Viena". En esta ocasión, el Consejo de Europa amplía la solicitud para la introducción de criterios ambientales en políticas sectoriales diferentes. Igualmente encarga a la Comisión un informe sobre la situación de la integración de criterios ambientales en políticas sectoriales. En diciembre de 1999 tiene lugar la "Cumbre de Helsinki". En este foro, la Comisión Europea presenta el "Informe Cardiff" en el que se relacionan todos los avances globales en cuanto a la integración de criterios ambientales y desarrollo sostenible. También en esta Cumbre, la Comisión presenta un informe sobre indicadores de integración.

Es preciso hacer notar que, desde que en la "Cumbre de Cardiff" surgiera la exigencia de un plan para el desarrollo estratégico sobre integración de criterios para el desarrollo sostenible, han sido muchos y muy variados los documentos elaborados y los esfuerzos realizados en torno a la consideración pormenorizada de los diferentes sectores y la implicación y repercusiones de su actividad en el medio ambiente. En 2001 se emite la Comunicación al Consejo y al Parlamento Europeo titulada "Diez años después de Río: Preparación de la Cumbre Mundial sobre el Desarrollo Sostenible de 2002" en la que se establecen las prioridades y medidas que deberán adoptarse para contribuir al éxito del décimo aniversario de la primera "Cumbre de la Tierra". Entre ellas se señala la de conseguir mayor equidad a escala mundial. Por otra parte, entre las cuatro líneas de acción consideradas para guiar los trabajos de la Cumbre, destaca la referida a erradicación de la pobreza para romper el círculo vicioso del empobrecimiento y la degradación del medio ambiente con un enfoque más integrado y coherente con los objetivos de desarrollo convenidos en el marco de las Naciones Unidas. También el «Consejo Europeo de Gotemburgo" adopta una estrategia de la Unión Europea para el desarrollo sostenible en la que se indica que es preciso promover tanto el crecimiento económico y la cohesión social, como la protección del medio ambiente.

El "Sexto Programa Comunitario en Materia de Medio Ambiente", en una Comunicación elaborada en enero de 2001, denominada: "Medio Ambiente 2010: el futuro está en nuestras manos", se plantea un nuevo enfoque proponiendo un amplio diálogo y participación de autoridades, ONG e industrias para una participación mayor en la aplicación de medidas medioambientales. El "Sexto Programa", que entra en vigor en septiembre de 2002, se plantea unos objetivos centrados en las siguientes prioridades: mejorar la aplicación de la legislación medioambiental; profundizar en la integración de criterios medioambientales en las políticas sectoriales; implicar a los ciudadanos y mejorar sus comportamientos; proteger y restaurar los recursos naturales y detener la pérdida de biodiversidad; conseguir un nivel de calidad ambiental sin efectos perniciosos para la salud; lograr que el consumo de recursos, renovables y no renovables, no supere la capacidad de carga del medio ambiente; y prevención y gestión de los recursos. Desde este nuevo enfoque se aboga por el uso prudente de recursos y protección del ecosistema mundial, indispensable para la prosperidad económica y desarrollo social equilibrado, buscando coherencia entre nuestros objetivos sociales, económicos y medioambientales 
PILAR SAURA CALIXTO Y MARÍA ÁNGELES HERNÁNDEZ PRADOS

LA EVOLUCIÓN DEL CONCEPTO DE SOSTENIBILIDAD Y SU INCIDENCIA EN LA EDUCACIÓN AMBIENTAL

para conseguir competitividad, crecimiento, rentabilidad y creación de empleo: «Es preciso tener en cuenta las implicaciones económicas y sociales de la actuación medioambiental cuando se intenta conseguir el desarrollo sostenible". En este sentido, el "Sexto Programa" trasciende la dimensión ambiental del desarrollo sostenible implicándose también la calidad de vida de los ciudadanos de la Unión Europea, en particular, y del planeta, en general. Por todo ello, el año 2001 puede considerarse decisivo ya que durante el mismo se produce una clara inflexión hacia un nuevo enfoque de la sostenibilidad que se manifiesta también en el cambio de las estrategias que se proponen.

En octubre de 2002, el Consejo de Medio Ambiente, en el apartado 9 de sus conclusiones relativas a la aplicación de la estrategia de desarrollo sostenible de la Unión Europea y a la dimensión medioambiental de los compromisos asumidos en la "Cumbre de Johannesburgo", insta a las formaciones del Consejo competentes en educación, sanidad, política del consumidor, turismo, investigación, empleo y política social a que "desarrollen estrategias para promover el desarrollo sostenible mediante la integración de los aspectos medioambientales en políticas y acciones actuales".

Resulta de especial interés, por lo que supone de reconocimiento sobre el papel central de la educación como promotora del desarrollo sostenible, la iniciativa adoptada en diciembre de 2002 por la Asamblea General de las Naciones Unidas, materializada en la Resolución (57/254), relativa al Decenio de las Naciones Unidas para la Educación con miras al Desarrollo Sostenible (2005-2014). En enero del 2005 esta Resolución es adoptada por consenso. En calidad de organismo responsable para la educación en el seno de las Naciones Unidas, la UNESCO es designada como órgano responsable de su promoción, asumiendo un papel determinante en la definición de normas de calidad aplicables a la educación para el desarrollo sostenible, orientando programas propios para integrar los cambios necesarios en la promoción de este modelo de desarrollo. En definitiva, se persigue mejorar la calidad de la enseñanza y reorientar sus objetivos tomando en cuenta la importancia del desarrollo sostenible según el nuevo enfoque, subrayando que la educación es un elemento indispensable para conseguir logros en este sentido.

Con estas prioridades, las Naciones Unidas deciden declarar la Década de la Educación para el Desarrollo Sostenible, dando respuesta a las exigencias de diversos acuerdos internacionales de llamada global por el desarrollo sostenible, asignando a la educación un papel que va más allá de la mera difusión de contenidos, asumiendo como tareas principales: fomentar el conocimiento de los principios en los que se asienta la sostenibilidad; implicar a todos los sectores sociales, empresas, gobiernos locales, medios de comunicación, etc., en el desarrollo e implementación de programas; propiciar la formación continua para todos, la capacitación permanente, la educación de calidad; plantear una reorientación de los programas educativos existentes en todos los países según el nuevo enfoque integrando conocimientos económicos, sociales y ambientales, así como destrezas, actitudes y valores inherentes a la sostenibilidad tales como solidaridad, cooperación, equidad, calidad de vida, justicia, etc. En este contexto, los gobiernos, con el apoyo de 
la sociedad civil, reconocen que el avance hacia el desarrollo sostenible depende de las acciones de los ciudadanos en todos los aspectos de la vida, lo que supone adoptar cambios en su manera de pensar, vivir y trabajar por lo que se establecen marcos de actuación con el fin de facilitar la participación, la concienciación y la capacitación. Es decir, la educación para un desarrollo sostenible. La educación para el desarrollo sostenible empieza a concebirse como una educación cívica, ética y moral en la que se integran principios y valores para la construcción de una ciudadanía crítica que propicie el análisis de la situación actual del planeta, intentando dar respuesta a las nuevas preocupaciones.

Nueva Ética de la Sostenibilidad. Modelo de Desarrollo humano

\begin{tabular}{|c|c|c|c|}
\hline Años & Situación & Foros & $\begin{array}{l}\text { Planteamientos y } \\
\text { recomendaciones }\end{array}$ \\
\hline $1990-2000$ & $\begin{array}{l}\text { - Debate social } \\
\text { sobre el desarrollo } \\
\text { humano } \\
\text { - Interés por la } \\
\text { defensa de la justi- } \\
\text { cia social } \\
\text { - Se plantea el uso } \\
\text { racional de recur- } \\
\text { sos y respeto } \\
\text { hacia los mismos } \\
\text { - Consideración de } \\
\text { las dimensiones } \\
\text { socioculturales, } \\
\text { políticas y econó- } \\
\text { micas en las rela- } \\
\text { ciones entre } \\
\text { medio ambiente y } \\
\text { humanidad } \\
\text { - Concienciación } \\
\text { sobre la interde- } \\
\text { pendencia entre } \\
\text { medio ambiente, } \\
\text { desarrollo y } \\
\text { educación }\end{array}$ & $\begin{array}{l}\text { - Conferencia de las } \\
\text { Naciones Unidas sobre } \\
\text { Medio Ambiente y } \\
\text { Desarrollo. "Cumbre de } \\
\text { la Tierra" (1992) } \\
\text { - Tratado de la Unión } \\
\text { Europea. Maastrich } \\
\text { (1992) } \\
\text { - Quinto Programa } \\
\text { Comunitario de Acción } \\
\text { en materia de Medio } \\
\text { Ambiente (1995-2000) } \\
\text { - Informe de la Comi- } \\
\text { sión sobre aplicación } \\
\text { comunitaria de medio } \\
\text { ambiente y desarrollo } \\
\text { sostenible. "Hacia un } \\
\text { Desarrollo Sostenible" } \\
\text { (1998) } \\
\text { - Tratado de Ámsterdam } \\
\text { (1999) } \\
\text { - Cumbre de Luxem- } \\
\text { burgo (1997) } \\
\text { - Cumbre de Cardiff } \\
\text { (1998) } \\
\text { - Cumbre de Helsinki } \\
\text { (1999) }\end{array}$ & $\begin{array}{l}\text { - Derecho a una vida digna } \\
\text { - Integración del concepto de } \\
\text { medio ambiente en todas las } \\
\text { políticas comunitarias } \\
\text { - Responsabilidad mundial en la } \\
\text { protección del medio ambiente } \\
\text { - Integración de las exigencias } \\
\text { ambientales en las diferentes } \\
\text { políticas comunitarias } \\
\text { - Establecimiento del principio de } \\
\text { responsabilidad compartida } \\
\text { - Atención a la información y su } \\
\text { difusión } \\
\text { - Necesidad de la educación para } \\
\text { asumir e interiorizar los nuevos } \\
\text { principios de la sostenibilidad } \\
\text { - Reorientación de la investigación } \\
\text { fundamental } \\
\text { - Consolidar la idea de desarrollo } \\
\text { sostenible dejando de constituir } \\
\text { una opción para convertirse en } \\
\text { obligación } \\
\text { - Promover el progreso econó- } \\
\text { mico y social y un alto nivel } \\
\text { de empleo } \\
\text { - Elaboración de estrategia para } \\
\text { introducir el principio de inte- } \\
\text { gración del medio ambiente } \\
\text { en todas las políticas de forma } \\
\text { transversal } \\
\text { - Puesta en práctica del Protocolo } \\
\text { de Kyoto } \\
\text { - Insistencia en la introducción de } \\
\text { criterios ambientales en políticas } \\
\text { sectoriales diferentes }\end{array}$ \\
\hline
\end{tabular}



EN LA EDUCACIÓN AMBIENTAL

\begin{tabular}{|c|c|c|c|}
\hline Años & Situación & Foros & $\begin{array}{l}\text { Planteamientos y } \\
\text { recomendaciones }\end{array}$ \\
\hline & & $\begin{array}{l}\text { - Sexto Programa Comu- } \\
\text { nitario en Materia de } \\
\text { Medio Ambiente } \\
\text { (2001) } \\
\text { - Comunicación de la } \\
\text { Comisión al Consejo, } \\
\text { al Parlamento, al } \\
\text { Comité Económico y } \\
\text { Social y Comité de las } \\
\text { Regiones. "Medio } \\
\text { Ambiente 2010: el } \\
\text { futuro está en nuestras } \\
\text { manos" (2001) } \\
\text { - Cumbre Mundial sobre } \\
\text { Desarrollo Sostenible. } \\
\text { Johannesburgo (2002) } \\
\text { - Decenio de las Nacio- } \\
\text { nes Unidas para la } \\
\text { Educación con miras al } \\
\text { Desarrollo Sostenible } \\
\text { (2005-2014) } \\
\text { - Comunicación de la } \\
\text { Comisión al Consejo } \\
\text { y al Parlamento } \\
\text { Europeo. "Diez años } \\
\text { después de Río: } \\
\text { Preparación de la } \\
\text { Cumbre Mundial sobre } \\
\text { Desarrollo Sostenible } \\
\text { de 2002" }\end{array}$ & $\begin{array}{l}\text { - Aplicar la legislación ambiental } \\
\text { - Participación de los ciudadanos } \\
\text { en la toma de decisiones } \\
\text { - Detener la pérdida de } \\
\text { biodiversidad } \\
\text { - Conseguir un nivel de calidad } \\
\text { ambiental sin efectos perniciosos } \\
\text { para la salud } \\
\text { - Logro de un consumo de recur- } \\
\text { sos renovables y no renovables } \\
\text { que no supere la capacidad de } \\
\text { carga del medio ambiente } \\
\text { - Desarrollo social equilibrado } \\
\text { - Lograr coherencia en la } \\
\text { cooperación internacional } \\
\text { para el desarrollo sostenible } \\
\text { - Integrar cambios necesarios para } \\
\text { la promoción de modelo de } \\
\text { desarrollo sostenible } \\
\text { - Implicar a todos los sectores } \\
\text { sociales, empresas, gobiernos, } \\
\text { medios de comunicación, etc., } \\
\text { en el desarrollo e implementa- } \\
\text { ción de programas de desarrollo } \\
\text { sostenible } \\
\text { - Coherencia entre objetivos socia- } \\
\text { les, económicos y medioambien- } \\
\text { tales y medios para conseguirlos } \\
\text { - Plantear la reorientación de } \\
\text { todos los programas educativos } \\
\text { existentes en todos los países } \\
\text { hacia los conocimientos econó- } \\
\text { micos, sociales y ambientales } \\
\text { así como destrezas, perspectivas } \\
\text { y valores propios de la } \\
\text { sostenibilidad } \\
\text { - La educación para el desarrollo } \\
\text { sostenible se concibe como una } \\
\text { educación cívica, ética y moral } \\
\text { - Educación para la construcción de } \\
\text { una ciudadanía crítica que propi- } \\
\text { cie el análisis de la situación actual } \\
\text { del planeta con el fin de dar } \\
\text { respuesta a las nuevas } \\
\text { preocupaciones y situaciones } \\
\text { - Equidad como medida a adoptar } \\
\text { para el desarrollo sostenible } \\
\text { - Erradicación de la pobreza }\end{array}$ \\
\hline
\end{tabular}




\section{LA EDUCACiÓN AMBiental y LA EVOluCión DEL CONCEPTO DE MEDio AMBIENTE}

El concepto de educación ambiental (EA) ha ido evolucionando en función de la percepción que sobre la idea de medio ambiente y sostenibilidad se tiene, facilitando, al mismo tiempo, el cambio hacia un nuevo enfoque de desarrollo sostenible, como puede verse en la siguiente tabla.

CONCEPTO DE SOSTENIBILIDAD EN LA EDUCACIÓN: EVOLUCIÓN (Análisis a partir de manifestaciones en foros internacionales)

\begin{tabular}{|c|c|c|c|}
\hline Años & Situación & Foros & $\begin{array}{l}\text { Planteamientos y } \\
\text { recomendaciones }\end{array}$ \\
\hline $\begin{array}{l}\text { Años } 60 \\
\text { (finales) }\end{array}$ & $\begin{array}{l}\text { - Notables avances de } \\
\text { la ecología } \\
\text { - Preocupación ante el } \\
\text { avance del deterioro } \\
\text { ambiental } \\
\text { - Necesidad de aporte } \\
\text { de conocimiento, } \\
\text { concienciación y } \\
\text { acción para detener } \\
\text { las modificaciones } \\
\text { ambientales }\end{array}$ & $\begin{array}{l}\text { Club de Roma } \\
\text { (1968). "Estudio com- } \\
\text { parativo sobre el } \\
\text { medio ambiente en } \\
\text { la escuela". Oficina } \\
\text { Internacional de } \\
\text { Educación. Ginebra. } \\
\text { UNESCO. }\end{array}$ & $\begin{array}{l}\text { - Notables avances de la } \\
\text { ecología } \\
\text { - Reivindicaciones de } \\
\text { movimientos conservacionistas } \\
\text { - Se establecen programas de } \\
\text { educación ecológica }\end{array}$ \\
\hline Años 70 & $\begin{array}{l}\text { - Destacan los } \\
\text { planteamientos del } \\
\text { movimiento ambien- } \\
\text { talista (pacifista, } \\
\text { antinuclear) } \\
\text { - Se utiliza por pri- } \\
\text { mera vez el con- } \\
\text { cepto de educación } \\
\text { ambiental (EA) }\end{array}$ & $\begin{array}{l}\text { - Conferencia sobre } \\
\text { Medio Ambiente } \\
\text { Humano. Esto- } \\
\text { colmo (1972) } \\
\text { - Conferencia Inter- } \\
\text { nacional de Edu- } \\
\text { cación Ambiental. } \\
\text { Belgrado (1975) } \\
\text { - Declaración de } \\
\text { Tbilisi (1977) }\end{array}$ & $\begin{array}{l}\text { - Destaca el movimiento } \\
\text { ambientalista pacifista, } \\
\text { antinuclear } \\
\text { - Nuevo enfoque de la EA } \\
\text { - La EA es objeto de atención } \\
\text { pública } \\
\text { - Aparecen diversas concepcio- } \\
\text { nes de EA (ambientalista, con- } \\
\text { servacionista, naturalista, } \\
\text { ecologista) } \\
\text { - Proyectos de EA orientados } \\
\text { principalmente hacia la ecolo- } \\
\text { gía con planteamientos próxi- } \\
\text { mos a las ciencias naturales } \\
\text { - Se recomienda no sólo la } \\
\text { "Sensibilización" de la pobla- } \\
\text { ción ante la situación ambien- } \\
\text { tal sino el cambio de actitudes } \\
\text { y comportamientos ante los } \\
\text { problemas ambientales } \\
\text { - Se huye de planteamientos } \\
\text { circunscritos excesivamente a } \\
\text { lo provincial }\end{array}$ \\
\hline
\end{tabular}


PILAR SAURA CALIXTO Y MARÍA ÁNGELES HERNÁNDEZ PRADOS

LA EVOLUCIÓN DEL CONCEPTO DE SOSTENIBILIDAD Y SU INCIDENCIA EN LA EDUCACIÓN AMBIENTAL

\begin{tabular}{|c|c|c|c|}
\hline Años & Situación & Foros & $\begin{array}{l}\text { Planteamientos y } \\
\text { recomendaciones }\end{array}$ \\
\hline Años 70 & & & $\begin{array}{l}\text { - Se establece uno de los princi- } \\
\text { pios básicos de la EA: Interac- } \\
\text { ción entre sociedad, desarrollo } \\
\text { y medio ambiente }{ }^{1}\end{array}$ \\
\hline Años 80 & $\begin{array}{l}\text { - Inquietud y preo- } \\
\text { cupación por el } \\
\text { desarrollo }\end{array}$ & $\begin{array}{l}\text { - Reuniones internacio- } \\
\text { nales sobre EA: Mana- } \\
\text { gua (1982), México } \\
\text { (1984), Bogotá (1985 } \\
\text { y 1988), Caracas } \\
\text { (1988), Buenos Aires } \\
\text { (1988) y Brasilia } \\
\text { (1989) } \\
\text { - Conferencia de Educa- } \\
\text { ción y Capacitación } \\
\text { Ambiental. Moscú } \\
\text { (1987) }\end{array}$ & $\begin{array}{l}\text { - La EA se formaliza en } \\
\text { programas y estructuras } \\
\text { gubernamentales } \\
\text { - Preocupación por los problemas } \\
\text { ambientales globales } \\
\text { - Interés por la relación entre } \\
\text { economía y medio ambiente } \\
\text { - Crítica a los modelos de desa- } \\
\text { rrollo económico } \\
\text { - Crítica a los modelos educati- } \\
\text { vos vigentes } \\
\text { - Pesimismo ante el incremento } \\
\text { en las disparidades del desarro- } \\
\text { llo en diferentes áreas }\end{array}$ \\
\hline Años 90 & $\begin{array}{l}\text { - Educación para } \\
\text { la sostenibilidad }\end{array}$ & $\begin{array}{l}\text { - Declaración de Talloi- } \\
\text { res (1991) } \\
\text { - Conferencia Mundial } \\
\text { de Naciones Unidas } \\
\text { sobre Medio Ambiente } \\
\text { y Desarrollo. Río de } \\
\text { Janeiro (1992) } \\
\text { - Foro Global hacia } \\
\text { Sociedades Sosteni- } \\
\text { bles y Responsabili- } \\
\text { dad Global (1992) } \\
\text { - Conferencia Interna- } \\
\text { cional "Ambiente y } \\
\text { Sociedad: Educación y } \\
\text { conciencia pública } \\
\text { para la sostenibilidad". } \\
\text { Tesalónica (1997) } \\
\text { - II Congreso Iberoame- } \\
\text { ricano de EA. México } \\
\text { (1997) }\end{array}$ & $\begin{array}{l}\text { - Se acepta el uso de la denomi- } \\
\text { nación Educación para el Desa- } \\
\text { rrollo Sostenible (EDS) } \\
\text { - La EA es considerada indispen- } \\
\text { sable para el cambio de actitu- } \\
\text { des, comportamientos y } \\
\text { adquisición de valores en con- } \\
\text { sonancia con el desarrollo sos- } \\
\text { tenible (Cáp. 36, Agenda 21) } \\
\text { - Se enfatiza en la capacidad de } \\
\text { la EA para promover el cambio } \\
\text { social } \\
\text { - La educación es un derecho de } \\
\text { todos } \\
\text { - Se acuñan los conceptos: cali- } \\
\text { dad de vida, ética ambiental, } \\
\text { equidad } \\
\text { - La EA es definida como Educa- } \\
\text { ción para el medio ambiente y } \\
\text { la sostenibilidad (EMAS) } \\
\text { - Se propone que la educación } \\
\text { es uno de los tres componentes } \\
\text { de la "gobernabilidad" total } \\
\text { (junto con las Instituciones y } \\
\text { Tecnología apropiada), que son } \\
\text { necesarios para originar la } \\
\text { sostenibilidad }\end{array}$ \\
\hline
\end{tabular}

1. Dos décadas antes de la Conferencia de Río. 
PILAR SAURA CALIXTO Y MARÍA ÁNGELES HERNÁNDEZ PRADOS

LA EVOLUCIÓN DEL CONCEPTO DE SOSTENIBILIDAD Y SU INCIDENCIA EN LA EDUCACIÓN AMBIENTAL

\begin{tabular}{|c|c|c|c|}
\hline Años & Situación & Foros & $\begin{array}{l}\text { Planteamientos y } \\
\text { recomendaciones }\end{array}$ \\
\hline $\begin{array}{l}\text { Años } \\
2000\end{array}$ & $\begin{array}{l}\text { - Distancia entre } \\
\text { las recomenda- } \\
\text { ciones formula- } \\
\text { das en los } \\
\text { diferentes foros } \\
\text { y las prácticas } \\
\text { concretas }\end{array}$ & $\begin{array}{l}\text { - II Congreso Iberoa- } \\
\text { mericano de Educa- } \\
\text { ción Ambiental. } \\
\text { Caracas (2000) } \\
\text { - Cumbre Mundial } \\
\text { sobre Desarrollo } \\
\text { Sostenible. Johan- } \\
\text { nesburgo (2002) } \\
\text { - IV Congreso Ibero- } \\
\text { americano de EA. } \\
\text { La Habana (2003) } \\
\text { - Carta de la Tierra. } \\
\text { Cátedra UNESCO } \\
\text { de EA (2003) } \\
\text { - Primer Congreso de } \\
\text { EA para el Desarro- } \\
\text { llo Sostenible. } \\
\text { Embalse, Córdoba, } \\
\text { Argentina (2004) } \\
\text { - Decenio de las } \\
\text { Naciones Unidas } \\
\text { para la Educación } \\
\text { con miras al Desa- } \\
\text { rrollo Sostenible } \\
\text { (2005-2014) }\end{array}$ & $\begin{array}{l}\text { - El concepto de sostenibili- } \\
\text { dad comprende no sólo el } \\
\text { medio ambiente sino tam- } \\
\text { bién la pobreza, población, } \\
\text { salud, seguridad alimenta- } \\
\text { ria, democracia, derechos } \\
\text { humanos y paz } \\
\text { - Se divulga el término } \\
\text { Educación para el Desarrollo } \\
\text { Sostenible (EDS) } \\
\text { - La sostenibilidad es consi- } \\
\text { derada como un imperativo } \\
\text { ético y moral } \\
\text { - La EA ha de situarse en el } \\
\text { territorio de la ética } \\
\text { - Importancia de la cultura } \\
\text { como pilar para el } \\
\text { desarrollo sostenible }\end{array}$ \\
\hline
\end{tabular}

Aunque el término educación ambiental (EA) se utiliza por vez primera a principios de los años 70 en la "Conferencia de Naciones Unidas sobre Medio Ambiente" (Estocolmo, 1972), ya en los 60 fueron puestos en práctica programas llamados de educación ecológica de carácter fundamentalmente conservacionista. Una de las primeras llamadas de atención sobre el problema ambiental se remonta al Club de Roma. En un Informe al Club, en 1972, sobre los límites del crecimiento se plantea que llegará un momento en el que será preciso elegir entre preparar la propia destrucción o la necesaria revolución cultural de los pueblos que introduzca profundos cambios en valores y conductas. Ya entonces se vislumbraba que no eran suficientes las soluciones tecnológicas para afrontar los problemas medioambientales. Eran precisas soluciones educativas, aunque hemos de reconocer que la atención en este contexto se centraba exclusivamente en el medio físico.

2. Principio no aceptado universalmente. 
PILAR SAURA CALIXTO Y MARÍA ÁNGELES HERNÁNDEZ PRADOS LA EVOLUCIÓN DEL CONCEPTO DE SOSTENIBILIDAD Y SU INCIDENCIA EN LA EDUCACIÓN AMBIENTAL

En la mencionada "Conferencia Internacional de las Naciones Unidas sobre el Medio Ambiente", celebrada en Estocolmo (1972), por primera vez se crea un programa de las Naciones Unidas para el Medio Ambiente (PNUMA), y es precisamente en el marco del PNUMA donde las Naciones Unidas se plantean la necesidad de diseñar un "Programa Internacional de Educación Ambiental" en colaboración con diferentes organizaciones no gubernamentales. En esta Conferencia se señala, no obstante, que el concepto de educación ambiental, durante su evolución, ha estado ligado estrechamente a la idea de medio ambiente tal y como éste se ha ido percibiendo, habiendo pasado desde una consideración puramente biológica y naturalista (conservacionista) a una nueva perspectiva más amplia que incluye aspectos políticos, económicos, sociales, culturales, además de las interacciones entre ellos.

El concepto de medio ambiente debe abarcar el medio social y cultural y no sólo el medio físico, por lo que los análisis que se efectúen deben tomar en consideración las interrelaciones entre el medio natural sus componentes biológicos y sociales y también factores culturales (UNESCO, 1978).

En 1975, tiene lugar el Seminario Internacional de Educación Ambiental que sirve de plataforma para la implementación del Programa de Educación Ambiental antes mencionado. En el seno de este Seminario se elabora la "Carta de Belgrado" como uno de los referentes más destacados para la educación ambiental, estableciéndose en este documento tanto sus objetivos como los conceptos fundamentales a tener en cuenta. Aunque en esta época proliferan proyectos de corte conservacionista, orientados hacia la ecología y las ciencias naturales, se señalan como objetivos: "Ayudar a las personas y grupos sociales a adquirir valores sociales y un profundo interés por el medio ambiental que los impulse a participar activamente en su protección y mejoramiento" (Objetivo 3). En este foro se marca como una de sus directrices básicas que «La EA debe considerar al ambiente en su totalidad -natural y creado por el hombre -, ecológico, económico, tecnológico, social, legislativo, cultural y estético".

Más tarde, en 1977, tiene lugar la "Declaración de Tbilisi" en el seno de la Conferencia Intergubernamental sobre Educación Ambiental en dicha localidad. En esta ocasión han de considerarse algunas aportaciones, entonces novedosas y hoy todavía vigentes, tales como la idea de educación ambiental como proceso permanente, dirigido no sólo a escolares, sino a personas de todas las edades y niveles educativos, tanto en el ámbito de la educación formal como no formal, proponiendo un enfoque desde la perspectiva de los valores, asumiendo plenamente la dimensión ética del problema. Se insiste en que no basta con sensibilizar, es preciso un cambio de actitud y actuación: "La educación debería preparar al individuo... propiciándole conocimientos técnicos y cualidades necesarias... con miras a mejorar la vida y proteger el medio ambiente, prestando la debida atención a los valores éticos... se debe adoptar un enfoque global». Desde esta nueva perspectiva se pone de relieve una clara preocupación por señalar la interdependencia entre 
economía, política y ecología, así como la relación estrecha entre sociedad, desarrollo y medio ambiente. No obstante, en esta ocasión, los programas se centran en denunciar problemas ambientales, sin abordar soluciones, ni señalar cauces para la formación, capacitación y acción a favor del medio ambiente.

Durante la década de los 80, la atención se centra en el carácter global de los problemas ambientales y en la interacción entre economía y medio ambiente. En 1987 se celebra en Moscú la "Conferencia de Educación y Capacitación Ambiental" en la que se debate sobre los modelos de desarrollo económico y modelos educativos vigentes, concretándose una estrategia internacional de acción en materia de educación y formación ambiental para el decenio de 1999. En 1991 tiene lugar la "Declaración de Talloires" en la que se enumeran hasta diez acciones necesarias para la "creación de un futuro equilibrado y sustentable para la humanidad, en armonía con la naturaleza", aludiendo a los cambios experimentados en el medio ambiente por causa de "una producción desequilibrada e insostenible y por patrones de consumo que agravan la pobreza en muchas regiones del mundo", señalando la dimensión global de los problemas medioambientales.

Como ya destacamos con anterioridad, la "Conferencia de Río" (1992) supone un hito importante en el cambio de mentalidad experimentado hasta el momento, considerándose a la educación ambiental como vehículo fundamental para el logro de comportamientos éticos en consonancia con el desarrollo sostenible. Efectivamente, en este foro se vincula el medio ambiente al desarrollo, con el término "desarrollo sostenible", acuñado a finales de los década de los 80, en el Informe Brundtland. Concretamente, en la Agenda 21 se recoge la estrategia global de acción (capítulo 36), que trata de la educación ambiental, con referencias constantes tanto a la educación y formación, como a la creación de una conciencia ambiental. Tanto en esta Conferencia como en el "Foro Global hacia Sociedades Sostenibles y Responsabilidad Global", celebrado el mismo año, se insiste en el valor de la educación para promover el cambio social, haciendo referencia a los conceptos de "ética ambiental" y "equidad".

En la Conferencia Internacional "Medio Ambiente y Sociedad: Educación y sensibilización para la sostenibilidad", celebrada en Tesalónica (1997), se vuelve a insistir en la necesidad de "cambios en los hábitos de producción y consumo", considerándose la educación "como pilar de acción a favor de la sostenibilidad junto con la legislación, la economía y la tecnología”. En esta ocasión se pone de manifiesto que no es posible transformar los vigentes patrones de desarrollo por un desarrollo sostenible sólo con la educación. Se entiende que la educación es uno de los tres componentes de la "gobernabilidad" global que son necesarios para hacer posible la sostenibilidad. Se consideran como bases fundamentales junto con la educación, la existencia de instituciones efectivas y la aplicación de una tecnología apropiada. Estos tres pilares constituyen la base que permite la interacción entre los componentes del desarrollo sostenible (economía, medio ambiente y sociedad). 
PILAR SAURA CALIXTO Y MARÍA ÁNGELES HERNÁNDEZ PRADOS LA EVOLUCIÓN DEL CONCEPTO DE SOSTENIBILIDAD Y SU INCIDENCIA EN LA EDUCACIÓN AMBIENTAL

Aunque las recomendaciones y planes de acción de Belgrado, Tbilisi, Moscú, etc., han sido determinantes, no fueron completamente exploradas como se reconoce en la "Reunión de Tesalónica", del año 2000. Ello ha dado lugar a que durante el primer decenio del siglo XXI se esté produciendo una progresiva toma de conciencia sobre la gran distancia existente entre declaraciones y realidad traducida en logros concretos. Hemos de resaltar, no obstante, el acuerdo generalizado sobre la idea de que en el concepto de sostenibilidad no sólo se implica el medio ambiente, que la sostenibilidad constituye un imperativo ético y moral, y que la EA debe situarse en el territorio de la ética. En este contexto, "necesitamos urgentemente una visión compartida sobre los valores básicos que brinden un fundamento ético para la comunidad mundial emergente" "Carta de la Tierra". IV Congreso Iberoamericano celebrado en La Habana, 2003). Se hace inaplazable «una educación basada en principios de esa nueva ética que va abriéndose paso, de una ética que atienda más al ser que al poseer» (Novo, 1996, 102). Quizás el reto más urgente que tengamos en los comienzos de este siglo es preparar a las jóvenes generaciones para responder a esta pregunta: ¿Es la Tierra meramente un medio de producción o es algo más, algo que es un fin en sí mismo? De la respuesta que se dé a esta pregunta dependerá la suerte de la "Tierra", y cuando decimos "Tierra" incluimos a todas las criaturas que hay en ella. ¿Qué se puede hacer?, se pregunta Commoner (1992, 183):

Soy consciente de que hay personas dispuestas a presentarse como abogados de los animales, bosques, campos y mares, que de otro modo no tendrían voz, e incluso del propio planeta. No obstante, la realidad sigue siendo que, de todos los seres vivos de la Tierra, sólo los humanos tenemos capacidad de cambiar conscientemente lo que hacemos. Si ha de haber paz con el planeta, nosotros debemos lograrla.

\section{4. ÚltTima REFLEXIÓN ABIERTA}

La EA debe hacerse eco de los cambios que se han producido en el tratamiento del problema medioambiental. Éste ha dejado de ser un problema que encuentra su adecuada respuesta en el ámbito científico y técnico para inscribirse también en el ámbito de la ética. Esto ha supuesto un cambio importante de concepción: «Pasar de concebir al hombre como dueño y propietario de su medio a entenderlo como usufructuario de ese medio y como miembro, en definitiva, de una comunidad biótica" (Sosa, 1989, 147). Empieza a considerarse en la EA el tránsito de una visión netamente antropocéntrica, de raíces kantianas, en la que las relaciones morales sólo se pueden establecer entre sujetos capaces de razonar y de asumir responsabilidades, a otra en que se piensa que también la naturaleza (el conjunto de los seres vivos) puede ser "objeto moral" en el sentido de poder exigir responsabilidades (Ortega y Mínguez, 2001). La ética ya no se limita a las relaciones entre las 
PILAR SAURA CALIXTO Y MARÍA ÁNGELES HERNÁNDEZ PRADOS

LA EVOLUCIÓN DEL CONCEPTO DE SOSTENIBILIDAD Y SU INCIDENCIA

EN LA EDUCACIÓN AMBIENTAL

generaciones presentes, ni siquiera a las relaciones interpersonales (Sosa, 1990), abarca también a nuestras relaciones con la naturaleza. Pero una modificación de las relaciones del hombre con su medio no se va a producir sin un cambio profundo en las actitudes y escalas de valores dominantes en la sociedad, es decir, sin un cambio cultural. Y sin esta nueva cultura, todo intento de hacer frente a los problemas medioambientales acabará por reproducir, tarde o temprano, los mismos problemas que ahora se intentan superar. "El problema planteado por el desastre ecológico que padecemos no es un problema técnico, ni económico, no es de medios, sino de fines. Es la civilización de los medios que ha hecho del progreso no la adecuación del hombre al medio natural, sino la adaptación del medio a las necesidades humanas creadas por el crecimiento económico" (Ortega y Mínguez, 2001). Éste es el reto de la EA. Si los seres humanos nos hemos dedicado hasta ahora a conocer el mundo y transformarlo, ha llegado la hora de que aprendamos a amarlo, conservarlo y protegerlo.

\section{Bibliografía}

Álvarez Díaz, J. (2001) De la política medioambiental a la integración del medio ambiente en las políticas sectoriales, en VV.AA. Medio ambiente y desarrollo sostenible. Ávila, Ediciones de Castilla y León.

Apple, K. (1999) Globalización y la necesidad de una ética universal. París, Debats.

Bonnet, M. (2003) Nature's Intrinsic Values, The Journal of the Philosophy of Education, vol. 37 (4), 629-639.

CARIDE, J. A. y MeIRA, P. A. (2001) Educación ambiental y desarrollo sostenible. Barcelona, Ariel. Commoner, B. (1992) En paz con el planeta. Barcelona, Crítica.

Gómez-Heras, J. M. ${ }^{a}$ (1997) Ética del medio ambiente. Madrid, Tecnos.

EscÁmez, J.; GarCía, R. y Pérez, C. (2003) La educación moral ante el reto de la pobreza, Teoría de la Educación. Revista Interuniversitaria, 15 y 185-212.

Gómez-Heras, J. M. ${ }^{a}$ (2005) Buscando la felicidad. Bilbao, Desclée de Brouwer.

JacoBs, M. (1997) La economía verde. Madrid, Icaria.

LEOPOLD, A. (2000) Una ética de la Tierra. Madrid, Catarata.

Molina del Pozo, C. F. (2002) Manual de Derecho de la Comunidad Europea. Madrid, Dijusa.

Novo, M. (1996) La educación ambiental. Bases éticas, conceptuales y metodológicas. Madrid, Universitas.

Öhman, J. (2006) Pluralism and criticism in environmental education and education for sustainable development: a practical understanding, Environmental Education Research, vol. 12 (2), 149-163.

Ortega, P. y Mínguez, R. (2001) La educación moral del ciudadano de hoy, Barcelona, Paidós.

- (2003) Educar para una cultura medioambiental, Revista de Educación, MEC, número extraordinario, 271-294.

Papastephanou, M. (2005) Globalisation, Globalism and Cosmopolitanism as an Educational Ideal, Educational Philosophy and Theory, vol. 37 (4), 533-551.

Sosa, N. (1989) La ética en la educación ambiental, en Sosa, N. (comp.) Educación ambiental. Sujeto, entorno y sistema. Salamanca, Amarú.

- (1990) Ética ecológica. Madrid, Libertarias. 
PILAR SAURA CALIXTO Y MARÍA ÁNGELES HERNÁNDEZ PRADOS

LA EVOLUCIÓN DEL CONCEPTO DE SOSTENIBILIDAD Y SU INCIDENCIA EN LA EDUCACIÓN AMBIENTAL

\section{DOCUMENTOS INTERNACIONALES Y COMUNITARIOS}

Tratado fundacional de la Comunidad Europea (CEE, 1950).

Iniciativa del Parlamento Europeo sobre contaminación atmosférica (1968).

Convenio de Oslo para el Atlántico Norte (1972).

Conferencia de Naciones Unidas sobre Medio Ambiente. Estocolmo (1972).

Cumbre de París (1972).

Convenio de Londres (1973).

Primer Programa Plurianual Comunitario en materia de Medio Ambiente (1972 a 1977).

Conferencia Internacional de Educación Ambiental. Belgrado (1975).

Segundo Programa Pluarianual Comunitario en materia de Medio Ambiente (1977 a 1982).

Declaración de Tbilisi (1977).

Tercer Programa Comunitario de Acción en Materia de Medio Ambiente (1983 a 1986).

Primera modificación del Tratado de Roma por el Acta Única Europea.

Informe Brundtland. "Nuestro futuro común". Comisión Mundial para el Medio Ambiente y el Desarrollo (1987).

Resolución sobre la Educación en Materia de Medio Ambiente. Ministros de Educación reunidos en Consejo (1988).

Cuarto Programa Comunitario de Acción en Materia de Medio Ambiente (1987 a 1992).

Declaración de Talloires (1991).

Conferencia de Educación y Capacitación Ambiental. Moscú (1987).

Conferencia de Naciones Unidas sobre Medio Ambiente y Desarrollo "La Cumbre de la Tierra". Río de Janeiro (1992).

Tratado de la Unión Europea Maastrich (1992).

Foro Global hacia Sociedades Sostenibles y Responsabilidad Global (1992).

Quinto Programa Comunitario de Acción en materia de Medio Ambiente (1995-2000).

Informe de la Comisión sobre la Aplicación comunitaria de medio ambiente y desarrollo sostenible. "Hacia un Desarrollo Sostenible" (1998).

Tratado de Ámsterdan (1999).

Cumbre de Luxemburgo (1997).

Declaración de Tesalónica (1997).

Cumbre de Cardiff (1998).

"Agenda 2000" (2000-2006).

Cumbre de Viena (1998).

Cumbre de Helsinki (1999).

Sexto Programa Comunitario en Materia de Medio Ambiente (2001).

Comunicación de la Comisión al Consejo, al Parlamento Europeo, al Comité Económico y Social y Comité de las Regiones. “Medio Ambiente 2010: el futuro está en nuestras manos" (2001).

Cumbre Mundial sobre Desarrollo Sostenible. Johannesburgo (2002).

Carta de la Tierra. Cátedra Unesco de EA (2003).

Decenio de las Naciones Unidas para la Educación con miras al Desarrollo Sostenible (20052014).

Comunicación de la Comisión al Consejo y el Parlamento Europeo. "Diez años después de Río: preparación de la Cumbre Mundial sobre el Desarrollo Sostenible de 2002”. 